\title{
Does a 48-Hour Rule Predict Outcomes in Patients with Acute Sigmoid Diverticulitis?
}

\author{
Jessica Evans • Robert Kozol • Wayne Frederick • \\ Anthony Voytavich • William Pennoyer • \\ Alexandra Lukianoff • Jennifer Lardner
}

Received: 17 March 2008 / Accepted: 26 March 2008 /Published online: 31 May 2008

(C) 2008 The Society for Surgery of the Alimentary Tract

In the above-mentioned article, published in Journal of Gastrointestinal Surgery online via SpringerLink on January 3, 2008 and appearing in Volume 12, Number 3, pages 577-582, six of the seven authors names were inadvertently omitted. The correct list of authors and their affiliations is shown above.

The online version of the original article can be found at http://dx.doi. org/10.1007/s11605-007-0405-7

J. Evans $(\bowtie) \cdot$ R. Kozol $\cdot$ W. Pennoyer $\cdot$ A. Lukianoff $\cdot$ J. Lardner Department of Surgery, University of Connecticut,

School of Medicine,

Storrs, CT, USA

e-mail: jessicahartford2003@yahoo.com

W. Frederick

Department of Surgery, Howard University, School of Medicine,

Washington, DC, USA

A. Voytavich

Department of Medicine, University of Connecticut,

School of Medicine,

Storrs, CT, USA 